\title{
Influence of hydrological factors on reservoir algal blooming
}

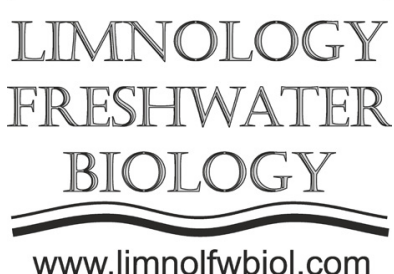

\author{
Datsenko Y.S.*, Puklakov V.V., Edelstein K.K. \\ Lomonosov State University, Moscow
}

\begin{abstract}
Based on model calculations of phytoplankton biomass over a long period in the Mozhaisk reservoir, the role of hydrological factors in fluctuations of production processes in the reservoir is analyzed. Among the hydrological factors, the most important for reservoir blooming is the reservoir filling mode in the spring and the volume of flood water intake in the summer. Sharp fluctuations in the phytoplankton development during the growing season are mainly due to the contrast of weather conditions, which determines the change of phases of cold weather to hot windless.
\end{abstract}

Keywords: phytoplankton, production processes, hydrometeorological factors, reservoir, modeling.

The leading role in the functioning of freshwater ecosystems belongs to phytoplankton, due to photosynthesis, which creates the production of organic matter that forms the material and energy basis of the circulation of matter in the reservoir. Ecosystems are characterized by changes in their parameters and characteristics over time due to fluctuations in external abiotic factors.

In this paper we consider the influence of leading hydrological factors on the development of production processes in the reservoir. These factors are related to the processes of external water exchange of the reservoir (water balance) and are determined by the hydrological regime of the rivers filling the reservoir and the regime of flow regulation by the hydroelectric power station unit. In addition, the intensity of production processes largely depends on fluctuations in hydrometeorological conditions during the growing season, which determine the characteristics of internal water exchange and the nature of thermodynamic processes in the reservoir.

The analysis of the influence of hydrological factors was carried out by the basis of a model calculation of long-term (for a 55-year period) fluctuations in production processes in the Mozhaisk reservoir near Moscow, which regulates the flow of the Moscow river for many years. Calculations were performed using a two-dimensional vertical simulation hydroecological model of GMV-MSU, in the ecological block of which the average daily characteristics of the composition of water and biomass of diatoms and blue-green algae in the meter layers of various compartments, into which the entire water column of the Mozhaisk reservoir is divided. A detailed description of the model is given in the work (Puklakov et al., 2015)
The result of the statistical analysis allows to establish the correlation relationships of the main characteristics of the base types of phytoplankton and a complex of selected abiotic factors, including characteristics of the hydrological regime of the reservoir, meteorological conditions during the growing season, the magnitude of the nutrient load on the reservoir. The following issue may be made from this analysis.

- A steady trend of increasing the average phytoplankton biomass during the growing season has been identified in the reservoir.

- If there is a large volume of spring flooding, we should expect a decrease in the average productivity of the reservoir, provided that there are no or insignificant summer-autumn rain floods. When summer floods are high, the primary productivity of the reservoir increases dramatically. Thus, it is the flood runoff that forms the external biogenic load on the reservoir during the growing season that determines the level of development of the reservoir's phytoplankton.

- If the large volume of winter water remaining during the reservoir filling period by comparison to the volume of high water, the greater average productivity of the reservoir will occur in reservoir.

- The value of the reservoir's pre-spring run-off contributes to a decrease in reservoir productivity during the growing season.

- Water temperature and air temperature have a significant impact on the duration of flowering period. The beginning of blue-green algae blooming in the reservoir is closely related to the average air temperature.

- The least predictable spring blooming in the 
reservoir applies to diatoms, which is most poorly associated with the main abiotic factors.

Spring blooming of the reservoir is determined by diatoms, is short-living (from 4 to 28 days) and depends, first, on the intensity of filling of the reservoir with flood water and the amount of dissolved nutrients brought by it, and, secondly, on the duration of intensive convective mixing in calm weather during the warming of the surface layer of water from 0 to $10^{\circ} \mathrm{C}-15^{\circ} \mathrm{C}$, favorable for the development of cold-loving diatoms.

From the complex of hydrological and water management factors considered by us that could influence diatoms blooming, a highly significant relationship of diatoms biomass was found with the intensity of reservoir filling in high water. This relationship shows that the slower the reservoir is filled, the more likely it is to have a higher average biomass value during the diatom flowering period. If spring processes in the catchment area are poorly developed, most of the spring water enters the reservoir in the form of a more Biogen-rich soil flow, rather than the slope flow characteristic of a stormy spring. In addition, with a long cold spring in the reservoir, the temperature conditions favorable for cold-loving diatoms are maintained longer. The input of biogenic elements (both external and internal loads) significantly correlates with the duration of flowering and maximum values of diatoms' biomass in the middle area of the reservoir.

For blue-green algae, significant correlations were found with hydrological factors: the volume of water inflow during summer and autumn floods, the coefficient of water exchange of the reservoir in high water, and the rate of intra-water transport of water masses. A significant influence on the development of blue-green algae is the wind speed and the number of calm days, as well as the ratio of the volume of water in the reservoir at the end of its winter working with the volume of flood waters.

Less significant was the relationship of flowering with the arrival of solar radiation and water temperature in the summer. However, none of the factors considered can be considered dominant in assessing the phytoplankton biomass in the reservoir.

Experimental and computational methods were used to analyze the dependence of reservoir blooming characteristics on changes in weather conditions during the growing season. The longer the period of short-term cooling of the reservoir, the more the water surface temperature decreases during this phase. Sharp changes in phytoplankton biomass occur when the weather changes from the cold phase to the warm phase with sunny and windless weather. In the phase of cold and cloudy weather with emerging convective-wind vortices, the small biohydrochemical cycle of substances in the epilimnion changes to a large cycle of biogenic substances due to the destruction of stratification and involvement in mixing of hypolimnion waters saturated with regenerated biogenic substances in silts and in the bottom anaerobic layer of water. This pattern is shown by a statistically significant relationship between the integral weather contrast index and the cyanobacteria bloom index in a nearly half-century-long series of low-flow stratified reservoir bioproductivity fluctuating from year to year in the summer-autumn period. However, there are exceptions to this pattern. For example, the two-phase summer-autumn season of 2003, which was characterized by abnormally warm and exceptionally rainy weather with high-water summer-autumn floods with a high content of nutrients in the water.

\section{Acknowledgements}

This work was supported by RFBR grants No. 18-05-01066.

\section{References}

Puklakov V.V., Datsenko Yu.S., Goncharov A.V. et al. 2015. Gidroekologicheskiy rezhim vodokhranilishch Podmoskov'ya (nablyudeniya, diagnoz, prognoz) [Hydroecological regime of reservoirs in the Moscow region]. Moscow: Pero. (in Russian) 